\title{
"marcadores moleculares em CÂncer de mama preditivos de metástases aXILAREs"
}

A presença de metástase nos linfonodos axilares é isoladamente o fator prognóstico mais importante para predizer o intervalo livre de doença e sobrevida global em pacientes com câncer de mama. Para tumores de tamanho semelhantes, as mulheres sem comprometimento linfáticoterão uma chance de sobrevida por cinco anos 20\% maior do que aquelas com linfonodos positivos'.

número de linfonodos a cometidos pela metástase constitui outro importante fator prognóstico. Um número maior de linfonodos positivos se associa à recidiva mais precoce e diminuição da sobrevida global.

Tradicionalmente, como ocorre em diversos tumores sólidos, a invasão linfática ou sangüínea peritumoral é o fator que mais se relaciona com a presença de metástase linfonodal, e nas neoplasias mamárias tem correlação mais estreita que o tamanho tumoral ou o grau histológico na previsão do comprometimento metastáticoaxilar. A identificação de novos marca dores moleculares despertou o interesse sobre o papel destes no prognóstico e indiretamente na seleção da terapêutica a djuvante. Alguns autores já haviam procura do correla cionar o tipo de expressão de alguns deles com as metástases axilares²5. Todavia, a análise conjunta destes marcadores moleculares apresentados pelos autores é inédita na literatura.

A confirmação do tipo histológico e grau de diferenciação dos cânceres de mama, bem como do seu perfil imunoistoquímico, tem sido frequentemente realizada antes do início da tera pia cirúrgica por meio das biópsias percutâneas com agulha grossa ou por sistema de vácuo-aspiração. Tal prática tem permitido o planeja mentotera pêutico mais a dequa do, individualizando no pré-operatório qual a melhor modalidade de tratamento local e sistêmico. A seleção das pacientes com tumores TI e T2 de mama e axila negativa que se beneficiarão da biópsia dolinfonodo sentinela é tema de grande interesse, uma vez que muitas a presentam o exame do linfonodo sentinela negativo no exame intra-operatório, e demonstram metástase no exame de parafina. Para estas pacientes há um acréscimona morbida de do tratamento, em virtude da necessidade de nova intervenção cirúrgica para o esvaziamento axilar total.

Identificar no pré-operatório as pacientes com axila negativa ao exame clínico, que apresentam risco para metástase axilar, seria importante durante a discussão da indicação da biópsia do linfonodo sentinela ao esvaziamento axilar total.

Os a utores registraram, em I 24 casos de câncer de mama, alguns fatores prognósticos moleculares freqüentemente analisados em tumores mamários, procurando correlacioná-los com as metástases linfonodais axilares. Além disso, na análise da invasão linfática e sangüínea, os autores utilizaram além da coloração tecidual habitual pela hematooxilina-eosina, os marcadores de endotélio vascular (CD3 I) e o marcador seletivo de endotélio linfático (D2-40).
Dentre os marcadores moleculares analisados, destacaram os receptores de estrógeno e progesterona, o Ki-67, o p53, o HER2. Os receptores hormonais positivos se relacionam estreitamente com tumores histologicamente bem diferencia dos e resposta à hormoniotera pia. A proteína Ki67 é um indicador de prognóstico adverso, e sua hiperexpressão se correlaciona com atividade mitótica elevada, indiferenciação celular e maior tendência a invasão. A proteína p53 é um gene supressor tumoral que regula o crescimento celular, bloqueando a replicação celular a normal e a transformação maligna. As mutações do p53 promovem o crescimento desordenado das células tumorais, sendo responsáveis por maior agressividade tumoral. $\bigcirc$ oncogene HER2 tem motivado amplas pesquisas, e estima-se que $20 \%$ a $30 \%$ das pacientes apresentam sua amplificação e/ou superexpressão. Estas evoluem pior do que a quelas que a presentam expressão normal ${ }^{6}$. Além disso, ele tem sido associado, quando avaliado como única variável, a uma resistência a quimioterapia e hormonioterapia, aumento da recidiva local, e diminuição da sobrevida em pacientes com linfonodos negativos. A ecaderina exerce importante papel na regulação da adesão intercelular em tecidos epiteliais. No câncer de mama parece existir uma significativa correlação entre a perda da expressão da e-caderina e outros indicadores de prognóstico ruim, como o tamanho tumoral e metástase axilar.

Apesar da inegável importância destes marcadores moleculares no prognóstico e manejo terapêutico de pacientes com câncer de mama, a invasão linfática e sangüínea continua sendo a variável mais importante na previsibilida de de metástase axilar demonstrada pelos autores.

\section{Marcos Desidério Ricc Paulo Augusto de Almeida Junqueira}

Referências

I. Fisher B, Bauer M, Wickerham DL, Redmond CK, Fisher ER, Cruz AB, et al. Relation of number of positive axillary nodes to the prognosis of patients with breast cancer. Cancer. 1983;52(9): 1551-7.

2. Brenin DR, Manasseh DM, El-Tamer M, Troxel A, Schnabel F, Ditkoff BA, et al. Factors correlating with lymph node metástases in patients with $\mathrm{TI}$ breast câncer. Ann Surg Oncol. 200 I;8(5):432-7.

3. Markopoulos C, Kouskos E, Gogas H, Mandas D, Kakisis J, Gogas J. Factors affecting axillary lymph node metástases in patients with $\mathrm{TI}$ breast carcinoma. Am Surg. 2000; 66(1 I): 1011-3

4. Bader AA, TioJ, Petru E, Buhner M, Pfahlberg A, Volkholz H, Tulusan AH. TI breast câncer: identification of patients at low risk of axillary lymph node metástases. Breast Cancer Res Treat. 2002;76(1):11-7.

5. Gajdos C, Tartter PI, Bleiweiss IJ. Lymphatic invasion, tumor size, and age are independent predictors of axillary lymph node metastases in women with $\mathrm{TI}$ breast cancers. Ann Surg. 1999;230(5):692-6.

6. Ross JS, Fletcher JA. The HER-2/neu oncogene in breast cancer: prognostic factor, predictive factor, and target for therapy. Stem Cells. 1998; I 6(6):4 I 3-28. 7. Marinho VFZ, Metze K, Sanches FSF, Rocha GFS, Gobbi H. Marcadores moleculares em câncer de mama preditivos de metástases axilares. Rev Assoc Med Bras. 2008;54(3)203-7. 